\title{
Urinary Ascites and Transient Intestinal Obstruction in a Preterm Infant: An Interesting Case of Posterior Urethral Valve
}

\author{
$\begin{array}{llll}\text { S. Mani, MD } & \text { F. Kupferman, MD } & \text { K. Kumar, MD } & \text { S. Hazra, MD }\end{array}$ M. Sokal, MD $^{1}$ \\ D. Jean-Baptiste, $M^{1} \quad$ R. Kim, $M D^{1}$
}

${ }^{1}$ Division of Neonatology/Nephrology, Department of Pediatrics, Brookdale Hospital Medical Center, New York, New York

Address for correspondence S. Mani, MD, Division of Neonatology/ Nephrology, Department of Pediatrics, Brookdale Hospital Medical Am J Perinatol Rep 2019;9:e209-e212. Center, New York, NY 11212 (e-mail: drvazan@gmail.com).

\begin{abstract}
Keywords

- posterior urethral valve

- urinary ascites

- preterm infant

- hypoalbuminemia

- nonimmune hydrops fetalis

- anemia

- intestinal obstruction

Posterior urethral valve (PUV) is the most common congenital cause of bladder outflow obstruction in male neonates. We report a preterm neonate with PUV who presented as nonimmune fetal hydrops with intestinal obstruction in the antenatal period. The mother of our patient is a 33-year-old woman who started her prenatal care at our hospital at 30 weeks' gestation. Her sonogram done at 32 weeks in our hospital revealed fetal hydrops. It showed polyhydramnios, mild pyelectasis of right kidney, normal left kidney, and fetal ascites. Amniocentesis revealed bile stained amniotic fluid. Ultrasound during the procedure showed dilated fetal bowel loops with increased echoes. Following delivery at 32 weeks postnatal exam showed ascites with absence of skin edema, pleural, or pericardial effusion. The abdominal sonogram showed distended urinary bladder and bilateral hydroureteronephrosis. Bladder catheterization was done which relieved the bladder outlet obstruction. Voiding cystourethrogram was done later which confirmed PUV and bilateral grade 5 vesicoureteral reflux. The formation of urinary ascites in PUV serves as a pop-off mechanism to relieve the intravesical and intrarenal pressure. When this happens by mechanisms other than bladder rupture, it can lead on to transient intestinal obstruction and hepatic synthetic defects.
\end{abstract}

Posterior urethral valve (PUV) is the most common congenital cause of bladder outflow obstruction in male neonates. More than $50 \%$ of the PUVs are diagnosed prenatally. ${ }^{1}$ Prenatal ultrasound findings include thick-walled bladder, the keyhole sign, unilateral or bilateral hydroureteronephrosis, echo bright kidneys, and oligohydramnios. ${ }^{2}$ Patients who are not detected prenatally usually are diagnosed as neonates or young infants. About half will present with urinary tract infections. ${ }^{1}$ Newborns will present with respiratory distress due to lung hypoplasia. Lung hypoplasia develops because of oligohydramnios. Some may present with abdominal distension due to enlarged overdistended bladder or urinary ascites, difficulty with voiding, or a poor urinary stream. ${ }^{3}$

received

September 13, 2018 accepted after revision May 2, 2019
DOI https://doi.org/

10.1055/s-0039-1692419. ISSN 2157-6998.
We present a 32-week preterm neonate with postnatally diagnosed PUV who presented as nonimmune fetal hydrops with intestinal obstruction in the antenatal period.

\section{Case Report}

\section{Prenatal Course}

The mother of our patient is a 33-year-old woman P1011 who had her prenatal care in St. Lucia which was uneventful except for sonogram done at 28 weeks' gestation revealed full fetal urinary bladder, and she was scheduled for followup. Her blood group was "A" positive and Coombs' test was negative. Her comorbidities included previous cesarean
Copyright $\odot 2019$ by Thieme Medical Publishers, Inc., 333 Seventh Avenue, New York, NY 10001, USA. Tel: +1(212) 584-4662.
License terms

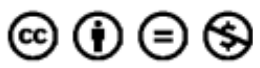


section, obesity (body mass index 41.6), and sickle cell trait. Patient started prenatal care at our hospital at 30 weeks' gestation. Routine prenatal laboratories were done during the initial visit. She was admitted to the labor and delivery at 32 weeks' gestation for preterm labor. She received magnesium sulfate and antenatal steroids. The sonogram done at 32 weeks at our hospital revealed fetal hydrops. It showed an amniotic fluid index 44 (polyhydramnios), biophysical profile $4 / 8$, expected fetal weight $3,424 \mathrm{~g}$ (>97\%), mild pyelectasis of right kidney, normal left kidney, fetal ascites, umbilical arterial Doppler, and middle cerebral artery (MCA) Doppler values were within normal limits. In view of polyhydramnios, therapeutic amniocentesis was performed under ultrasound guidance around $1,800 \mathrm{~mL}$ green colored fluid was removed from the amniotic cavity. Fluid was sent for cultures, glucose, and karyotyping. They were later reported as normal. There were no complications. Ultrasound during the procedure revealed dilated loops of fetal bowel, echogenic bowel, and small hepatic calcifications. Postprocedure amniotic fluid index was 14. Following the amniocentesis, the preterm labor subsided. Fetal echocardiogram was done by the pediatric cardiologist. The fetus was noted to have sinus tachycardia with normal intracardiac anatomy.

\section{Neonatal Course}

A male neonate was delivered by elective cesarean section at 32 with Apgar score of 7 at 1 minute and 9 at 5 minutes. Physical examination of the neonate showed tense distended abdomen with no organomegaly or skin edema. Initial postnatal radiograph did not show any evidence of pleural or pericardial effusion. The neonate was mechanically ventilated, received surfactant, and was started on total parental nutrition and enteral feeding was withheld. He was administered ampicillin and cefotaxime for sepsis cover pending blood culture.

In the absence of postnatal evidence of hydrops, evaluation for isolated neonatal ascites was initiated. The umbilical cord blood rapid plasma reagin test for syphilis was negative. The initial blood work showed a hematocrit of 43.2 with no fetomaternal blood group incompatibility. The neonate's blood group was A positive and Coombs' test was negative. Kleihauer-Betke's test was done to rule out fetomaternal hemorrhage and was negative. Blood chemistry done in the first few days showed hypoalbuminemia, increasing trend of blood urea nitrogen and creatinine, hyponatremia, and hyperbilirubinemia ( - Table 1). Total serum immunoglobulin $\mathrm{M}$, serum lipase, and cytomegalovirus DNA polymerase chain reaction were negative.

The abdominal sonogram showed moderate amount of perihepatic ascites, tiny gall stones, patent main portal vein, full urinary bladder, and bilateral hydroureteronephrosis. In view of suspicion of urinary ascites, diagnostic abdominal paracentesis was done which showed the presence of urea and creatinine. Nephrology and urology were consulted.

In view of distended urinary bladder and deranged renal parameters, provisional diagnosis of bladder outlet obstruction was made. Bladder catheterization was done with a 5-Fr feeding tube which promptly relieved the bladder obstruction and around $120 \mathrm{~mL}$ of urine was drained. The electrolyte abnormalities were corrected with appropriate fluid management (-Table 1). In view of PUV being the most common cause of bladder outlet obstruction in a male neonate, urology consult was obtained. Continuous bladder drainage was continued, and renal parameters gradually normalized. The abdominal distension gradually decreased and resolved. Hypoalbuminemia was corrected with albumin infusion. After the clinical status of the neonate improved, voiding cystourethrogram was done which confirmed PUV and bilateral grade 5 vesicoureteral reflux (VUR). Percutaneous vesicostomy was done. The neonate started prophylactic amoxicillin therapy for grade 5 VUR. In view of anemia with a downward trend of hematocrit, the neonate started iron and erythropoietin therapy to which the neonate responded.

In the absence of dysmorphology and clinical evidence of any other congenital anomaly, genetic evaluation was withheld. The neonate failed the hearing screen in both the ears which was done before discharge. Audiology follow-up was scheduled. The neonate was discharged home with urology and nephrology follow-up.

\section{Discussion}

Urinary ascites in PUV can occur because of rupture of calyceal fornices or transudation across the intact upper tract. It can also occur following the rupture of bladder wall. In obstructive uropathy, the upper tracts are subjected to high pressures in the intrauterine life. This affects the development of the kidneys and cystic renal dysplasia ensues. However, protective mechanisms do exist to prevent this irreversible damage to the kidneys. These protective mechanisms include VUR, bladder diverticula, and urine extravasation. ${ }^{4}$ Extravasation at the level of the fornices may result in the formation of perinephric urinoma which may remain contained or communicate freely with the peritoneal cavity, leading to urinary ascites. We consider this to be the mechanism behind the formation of urinary ascites in our patient.

Although oligohydramnios is the common presentation of severe PUV, polyhydramnios does occur due to unclear mechanisms. ${ }^{1,4,5}$ The amniocentesis done in our case showed bile stained amniotic fluid. We postulate that urinoma and full urinary bladder associated with the PUV led to transient bowel obstruction due to mass effect and that could explain the bile stained amniotic fluid. It could also be a possible mechanism for polyhydramnios.

We think that the urinoma was initially communicating freely with the peritoneal cavity which became contained later in the course. This resulted in the mass effect on the adjacent bowel loops. Postnatal renal parameters returned to normal soon after the bladder outlet obstruction was relieved. This showed that the kidneys were not subjected to high pressures for a long time. ${ }^{6}$

Fetal anemia accounts for 10 to $27 \%$ of hydrops. ${ }^{7}$ To evaluate the risk of fetal anemia, Doppler measurement of 
Table 1 Trend of Comprehensive Metabolic Panel of the infant in the first week of life

\begin{tabular}{|l|l|l|l|l|l|l|l|l|l|}
\hline $\begin{array}{l}\text { Laboratory parameter } \\
\text { (reference range) }\end{array}$ & Day 1 & Day 2 & Day 3 & Day 4 & Day 5 & Day 6 & Day 7 & Day 8 & Day 9 \\
\hline $\begin{array}{l}\text { Blood urea nitrogen } \\
(3-25 \mathrm{mg} / \mathrm{dL})\end{array}$ & 9.0 & 18.0 & 28.0 & 26.0 & 14.0 & 15.0 & 35.0 & 34.0 & 32.0 \\
\hline $\begin{array}{l}\text { Serum creatinine } \\
(0.3-1.0 \mathrm{mg} / \mathrm{dL})\end{array}$ & 1.00 & 1.30 & 1.80 & 1.90 & 0.90 & 0.60 & 1.20 & 0.80 & 0.60 \\
\hline $\begin{array}{l}\text { Serum sodium } \\
(130-145 \mathrm{mEq} / \mathrm{L})\end{array}$ & 131 & 125 & 126 & 140 & 135 & 145 & 154 & 146 & 136 \\
\hline $\begin{array}{l}\text { Serum potassium } \\
(3-6 \mathrm{mEq} / \mathrm{L})\end{array}$ & 4.8 & - & 6.0 & 6.2 & 3.5 & - & 5.5 & 5.3 & 4.5 \\
\hline $\begin{array}{l}\text { Serum chloride } \\
(97-108 \mathrm{mEq} / \mathrm{L})\end{array}$ & 98 & 92 & 94 & 105 & 101 & 108 & 119 & 110 & 103 \\
\hline $\begin{array}{l}\text { Serum bicarbonate } \\
(17-24 \mathrm{mEq} / \mathrm{L})\end{array}$ & 25 & 25 & 24 & 25 & 23 & 22 & 20 & 19 & 19 \\
\hline $\begin{array}{l}\text { Serum calcium, total } \\
(6.2-11 \mathrm{mg} / \mathrm{dL})\end{array}$ & 8.9 & 6.9 & 8.0 & 7.9 & 8.0 & 10.5 & 12.0 & 12.1 & 11.2 \\
\hline $\begin{array}{l}\text { Serum protein, total } \\
(3.6-6 \mathrm{~g} / \mathrm{dL})\end{array}$ & 3.7 & - & 4.0 & - & - & 7.1 & 6.6 & 7.2 & - \\
\hline $\begin{array}{l}\text { Serum albumin } \\
(3.0-3.9 \mathrm{~g} / \mathrm{dL})\end{array}$ & 1.8 & - & 1.9 & - & - & 3.9 & 3.6 & 4.2 & - \\
\hline $\begin{array}{l}\text { Serum alanine aminotransferase } \\
(13-45 \mathrm{U} / \mathrm{L})\end{array}$ & 22 & - & 30 & - & - & 26 & 14 & $<6$ & - \\
\hline $\begin{array}{l}\text { Serum aspartate aminotransferase } \\
(47-150 \mathrm{U} / \mathrm{L})\end{array}$ & 59 & - & 57 & - & - & 112 & 53 & 85 & - \\
\hline $\begin{array}{l}\text { Serum bilirubin, total } \\
(<8 \mathrm{mg} / \mathrm{dL})\end{array}$ & 3.2 & - & 10.9 & 13.5 & 13.1 & 16.0 & 12.8 & 11.7 & 7.6 \\
\hline $\begin{array}{l}\text { Serum bilirubin (conjugated) } \\
(<0.6 \mathrm{mg} / \mathrm{dL})\end{array}$ & 0.0 & - & 0.0 & 0.3 & 0.6 & 1.5 & 2.9 & 3.0 & 2.0 \\
\hline
\end{tabular}

the MCA peak systolic velocity should be performed in all hydropic fetuses after 16 weeks of gestation. This is an accurate noninvasive tool for predicting fetal anemia of any etiology. ${ }^{8,9}$

In case of suspected fetal anemia, fetal blood sampling is obtained by umbilical vein sampling, and the fetal hemoglobin level should be determined to exclude anemia as a cause of hydrops. ${ }^{10}$ In all reported cases with anemia and nonimmune hydrops fetalis (NIHF), hemoglobin values are less than $5 \mathrm{~g} / \mathrm{dL}^{8}{ }^{8}$ The mechanism for hydrops is thought to be high output cardiac failure.

In our patient, we had an abnormal MCA Doppler study. We did not do fetal cord blood sampling. The postnatal hemoglobin was $12 \mathrm{~g} / \mathrm{dL}$. Therefore, it is unlikely to be involved in the pathogenesis of hydrops fetalis in our case. Our patient did not have ABO incompatibility and direct Coombs' test was negative. There was no evidence of fetomaternal hemorrhage as well. We consider mild intrauterine hemolysis had occurred as evidenced by high reticulocyte count that led to the neonatal anemia. This can explain the gallstones observed in the antenatal sonograms.

Fetal renal regulation of fluid excretion is still unknown. Although both renal function impairment and elevated angiotensin levels may play a significant role in the etiology and pathogenesis of NIHF, hydrops can also occur without any significant renal damage and with normal urine production. ${ }^{11}$ Hypoproteinemia with decreased colloid osmotic pressure is frequently proposed as one of the causes of hydrops fetalis. Although it has been reported that low serum albumin levels occur in severely anemic neonates with hydrops, studies have shown that most fetuses with immune hydrops have an albumin concentration within the normal range; it suggests that hypoalbuminemia is unlikely to cause the initial development of nonimmune hydrops. ${ }^{12,13}$ Hypoalbuminemia thus seems to occur as a secondary effect in the cascade of hydrops (e.g., because of a reduced re-uptake of albumin from the interstitial compartment).

Hypoalbuminemia in our patient is likely due to the reduced hepatic synthesis of albumin secondary to compromised blood supply that could have resulted from the mass effect of the urinoma. We consider that the proteinuria seen in the postnatal life was probably due to the mild/transient kidney damage secondary to bladder outlet obstruction. This could be a contributing factor in hypoalbuminemia.

\section{Conclusion}

The formation of urinary ascites in PUV serves as a pop-off mechanism to relieve the intravesical and intrarenal pressures. When this happens by mechanisms other than bladder 
rupture, it can lead on to transient intestinal obstruction and hepatic synthetic defects.

\section{Conflict of Interest}

None.

\section{References}

1 Thakkar D, Deshpande AV, Kennedy SE. Epidemiology and demography of recently diagnosed cases of posterior urethral valves. Pediatr Res 2014;76(06):560-563

2 Chitrit Y, Bourdon M, Korb D, et al. Posterior urethral valves and vesicoureteral reflux: can prenatal ultrasonography distinguish between these two conditions in male fetuses? Prenat Diagn 2016;36(09):831-837

3 Macpherson RI, Leithiser RE, Gordon L, Turner WR. Posterior urethral valves: an update and review. Radiographics 1986;6 (05):753-791

4 Rittenberg MH, Hulbert WC, Snyder HM III, Duckett JW. Protective factors in posterior urethral valves. J Urol 1988;140(05):993-996

5 Krishnan A, de Souza A, Konijeti R, Baskin LS. The anatomy and embryology of posterior urethral valves. J Urol 2006;175(04): $1214-1220$

6 DeFoor W, Clark C, Jackson E, Reddy P, Minevich E, Sheldon C. Risk factors for end stage renal disease in children with posterior urethral valves. J Urol 2008;180(4, Suppl):1705-1708, discussion 1708

7 Forouzan I. Hydrops fetalis: recent advances. Obstet Gynecol Surv 1997;52(02):130-138

8 Mari G, Deter RL, Carpenter RL, et al; Collaborative Group for Doppler Assessment of the Blood Velocity in Anemic Fetuses. Noninvasive diagnosis by Doppler ultrasonography of fetal anemia due to maternal red-cell alloimmunization. N Engl J Med 2000;342(01):9-14

9 Borna S, Mirzaie F, Hanthoush-Zadeh S, Khazardoost S, RahimiSharbaf F. Middle cerebral artery peak systolic velocity and ductus venosus velocity in the investigation of nonimmune hydrops. J Clin Ultrasound 2009;37(07):385-388

10 Désilets V, Audibert F; Society of Obstetrician and Gynaecologists of Canada. Investigation and management of non-immune fetal hydrops. J Obstet Gynaecol Can 2013;35(10):923-938

11 Bellini C, Hennekam RC. Non-immune hydrops fetalis: a short review of etiology and pathophysiology. Am J Med Genet A 2012; 158A(03):597-605

12 Pasman SA, Meerman RH, Vandenbussche FP, Oepkes D. Hypoalbuminemia: a cause of fetal hydrops? Am J Obstet Gynecol 2006; 194(04):972-975

13 Phibbs RH, Johnson P, Tooley WH. Cardiorespiratory status of erythroblastotic newborn infants. II. Blood volume, hematocrit, and serum albumin concentration in relation to hydrops fetalis. Pediatrics 1974;53(01):13-23 